Leading Article

\title{
Caring for intravenous drug abusers with HIV infection: some lessons from Edinburgh
}

\author{
Philip D. Welsby
}

The Communicable Disease Unit, The City Hospital, Edinburgh EH10 5SB, UK.

The first patients with acquired immune deficiency syndrome (AIDS) were described in $1981 .{ }^{1}$ Initially the vast majority of patients were male homosexuals but soon it became apparent that intravenous drug abusers (IVDAs) were also a major at-risk group. Because of behaviour modification the 'first phase' epidemic of human immunodeficiency virus (HIV) infection in homosexuals is probably over, having become endemic. However the 'second phase' of epidemic HIV infection in most developed countries will be in the IVDA population. This phase may prove to be of greater significance because IVDAs are mostly heterosexual and will probably be the major 'critical bridge' by which HIV infection will spread into the heterosexual general population ${ }^{2}$ especially as IVDAs are often unable or unwilling to modify their behaviour. Worryingly, in the United States the proportion of AIDS patients attributable to heterosexual transmission is increasing more rapidly than in any other at-risk category. ${ }^{3}$

Before the advent of AIDS, IVDAs were of minor importance to medical services and society perceived IVDA as essentially a police problem. Six years later the rapidly increasing proportion of IVDAs with HIV infection ${ }^{4}$ necessitates a dramatic change in attitudes to IVDA. Doctors who now have male homosexuals as their HIV patients will soon have to face a very different group of 'second phase' patients.

To care for IVDAs as a group, some form of screening is necessary to plan for the future health care of those infected with HIV. In Edinburgh screening revealed the magnitude of future problems with preliminary laboratory reports suggesting a high prevalence of HIV infection in Edinburgh IVDAs ${ }^{5}$ and subsequently a general practice based study revealed (at least) $51 \%$ prevalence of HIV infection in a group of young people known to have abused intravenous drugs. ${ }^{6}$ If

Correspondence: P.D. Welsby, F.R.C.P.

Received: 20 January 1988 screening had not occurred we would be unaware of the predicted 104-160 IVDA patients that will be presenting with AIDS each year by 1991 in South East Scotland. ${ }^{7}$ Whilst philosophers ponder the numerous implications of such screening it is important to state that the results were essential for planning the future health care, costing about $£ 8$ million, of those (and others) who were tested. The spread of HIV infection in IVDAs in Edinburgh ${ }^{6}$ was unusual in its rapidity and spread elsewhere may be slower but attain a similar prevalence rate. ${ }^{8}$

In September 1986 the McClelland Report ${ }^{9}$ dealing with HIV infections and drug abuse recommended that IVDAs who cannot abstain (from IVDA) must be educated in safer drug taking practices, clean equipment should not be denied to those who cannot be dissuaded from injecting, clean needles and syringes could be issued on a one-for-one basis, substitution prescription should be considered for those who would be assisted to reduce or stop IVDA, safe sex counselling should be instituted, and police policies should be reviewed to ensure as much as possible that they do not prejudice infection control measures. Such a liberal approach will elicit hostile responses from many people, including some general practitioners who provide primary care for IVDAs. ${ }^{10}$

The Taylor Report in May $1987^{7}$ dealing with the health service implication of HIV infection provided predictions on which to base health care planning, and recommended that each area in Scotland should develop a specific HIV service, coordinated by a specialist unit. A consultant-supervised screening clinic ${ }^{11}$ was set up to provide a service so that patients who wanted to be counselled outwith STD clinics would not use blood donation as a means of being tested.

The problems and challenges when caring for homosexual AIDS patients are well known ${ }^{12}$ but there are numerous specific problems peculiar to IVDAs with HIV infection or AIDS. To care for individual IVDAs an initial realization must be made that neither the IVDA nor the HIV infection 
can be managed independently in individual patients. Because there is no evidence that any treatment is uniformly effective for IVDA, prescription of oral substitutes for intravenously abused drugs has been controversial. In the context of HIV substitution prescription is not to treat IVDA but rather to delay the postulated speedier progression to AIDS in those who continue to abuse drugs intravenously. Preliminary results suggest that medically supervised oral methadone reduces the amount of intravenous drug abuse and also slows the progression of HIV towards AIDS (Brettle, R.P., personal communication). Society may benefit in other ways from a more liberal provision of substitution prescription for IVDAs and politicians may well have to reassess their previous 'hardline' attitude to drugs. Indeed legalization of heroin, which abusers want above all else, has its advocates $^{13}$ but heroin provision would be reasonable only if supplied by trained professionals providing non-reusable needle syringe units. ${ }^{14}$ Society is unready for such radical solutions, perhaps preferring to continue to pay the horrendous emotional and financial cost of IVDA-related AIDS.

Many psychiatrists, who have been reluctant to care for IVDAs, will have to reconsider their position despite the paucity of proven therapies for treating IVDAs most of whom are not, and do not regard themselves, as mentally ill. For outpatient care IVDAs should ideally have separate outpatient facilities because 'normal' patients are often surprised and afraid when confronted with the unpredictable atmosphere of free-floating restlessness and aggression in waiting areas. Effective development of 'intensive outpatient care' as recommended for homosexuals is difficult for IVDAs because the attendance default rates are about $30 \%$ (Brettle, R.P., personal communication).

In the community IVDAs, unlike homosexuals, have no well developed self-help groups and 'care in the community' is difficult: homelessness will become a serious problem as it is already in New York. ${ }^{8}$ Parents of IVDAs often have been unable to cope with their childrens' IVDA problems, and will be even less able to cope with IVDA and HIV/ AIDS illnesses and thus facilities will be needed to cater for 'bed blocking' IVDAs. Hostels are appropriate for homosexuals but behavioural problems of some IVDAs will make hostel care difficult.

For in-patient care separate sex facilities are desirable: one third of HIV-positive IVDAs are female and some may be pregnant: facilities will have to be able to cater for mothers, fathers, and children, some or all of whom may have HIVrelated illness. Wards will need to be modified so that observation of patients is possible at all times and arrangements instituted so that ward drugs can be stored and dispensed under safe and secure conditions. The IVDA's visitors are often other IVDAs: non-prescribed drugs are brought on to wards and medical intravenous lines may be used for administration. Enforcement of restrictive visiting may be impossible, and perhaps would not be to the overall benefit of long stay patients with a limited life expectancy. Despite education some staff are reluctant to handle HIV-positive patients. This reaction, if combined with manipulative and aggressive behaviour of some IVDAs will cause problems in staff recruitment and retention.

When dealing with IVDAs doctors have to adopt the equalmindedness of William Osler ${ }^{15}$ and sus pend overly ambitious therapeutic objectives and expectations when treating addicted patients. 160 Although some IVDAs are thieves or have been involved in violent crime it is not the job of health care professionals to judge individuals (no matter what our personal thoughts about groups of such patients may be) and the adoption of a nonjudgemental approach is essential, not for (often pretentious) philosophical reasons, but in order to establish rapport by which IVDAs' behaviour can be affected for their benefit and for the benefit of society.

There is no doubt that the recently acquired problems of IVDAs constitute a challenge for health care professionals and for society: unfortunately the personal rewards of caring for IVDAs are less than almost any other form of patient care.

\section{References}

1. Pneumocystis pneumonia - Los Angeles. $M M W R$ 1981, 30: 250-252.

2. Moss, A.R. AIDS and intravenous drug abuse: the real heterosexual epidemic. $B r \operatorname{Med} J$ 1987, 294: 389-390.

3. PHS Plan for Prevention and Control of AIDS and the AIDS Virus. Public Health Rep 1986, 101: 341-348.

4. World Health Organisation Collaborating Centre on AIDS. AIDS Surveillance in Europe. Situation by October 31st 1986. WHO, Geneva, 1986.

5. Peutherer, J.F., Edmond, E., Simmonds, P., Dickson, J.D. \& Bath, G.E. HTLV-III antibody in Edinburgh drug addicts. Lancet 1985, ii: 1129-1130. 
6. Robertson, J.R., Bucknall, A.B.V., Welsby, P.D. et al. An epidemic of AIDS-related virus (HTLV-III/LAV) infection among intravenous drug abusers in a Scottish general practice. $\mathrm{Br}$ Med $J$ 1986, 292: 527-530.

7. Report of the National Working Party on Health Service Implications of HIV Infection (the Taylor Report). May 1987. Scottish Home and Health Department.

8. Weinberg, D.S. \& Murray, H.W. Coping with AIDS. The special problems of New York City. $N$ Engl $J$ Med 1987, 317: 1469-1473.

9. HIV infection in Scotland. Report of the Scottish Committee on HIV Infection and Intravenous Drug Misuse (the McClelland Report). Scottish Home and Health Department.
10. McKee, I. AIDS and heroin abuse in Edinburgh. Edinburgh Medicine 1987, February: 1.

11. Brettle, R.P., Bisset, K., Burns, S. et al. Human immunodeficiency virus and drug misuse: the Edinburgh experience. $\mathrm{Br}$ Med J 1987, 295: 421-424.

12. Adler, M.W. (ed) $A B C$ of AIDS. British Medical Journal, London, 1987.

13. Stevenson, R.C. The benefits of legalising heroin. Lancet 1986, ii: 1269-1270.

14. Welsby, P.D. One-use needle-syringe unit for drug abusers. Lancet 1987, ii: 285.

15. Osler, W. Aequanimitas 3rd Edition. McGraw, New York, 1932.

16. Drucker, E. AIDS and addiction in New York City. Am J Drug Alcohol Abuse 1986, 12 (1 \& 2): 165-181. 